\title{
Apptojo: Behavioral Relationship between Consumers and Food Merchants through a CRM Mobile Application
}

\author{
Uriel Cambrón Hernández, Mariela Chávez Marcial \\ Instituto Tecnológico Superior de Ciudad Hidalgo \\ Ingeniería en Sistemas Computacionales, Mexico \\ urcambron@gmail.com, marielawiroma@hotmail.com
}

\begin{abstract}
Emerging markets become part of a digital economy [1], in which the marketing of food is one of the most important supply lines in the topics of human consumption, the MiPymes of the State of Michoacán, Mexico, have a clear disadvantage to the large fast food chains, which have technologies (CRM) for the distribution and marketing of their products. The use of mobile technologies allows MSMEs the opportunity to compete with large chains, while creating a consumer experience, giving rise to a set of data that can de- termine the behavior of customers and companies. Apptojo emerges as a tool that provides a solution to link and make sales between customers and compa- nies, generating proposals of dishes visible to the customer and ordered by a dynamic system of geolocation and randomness of most consumed dishes.
\end{abstract}

Keywords: marketing, android, food, trends, CRM.

\section{Introduction}

Electronic commerce systems serve as a media pillar in emerging markets. Approximately every minute $\$ 862,823.00$ dollars are spent on online purchases [7]. Of this figure, a substantial percentage goes to electronics, clothing, furniture, and digital content; However, the percentage that goes to electronic food stores is almost imperceptible.

In the state of Michoacán, Mexico, the businesses of the food sector (MiPymes of food sales), have a clear problem when it comes to marketing their products through the Internet, resulting in a sinuous and sometimes counterproductive process in the investment aspect -benefit that can be obtained; subtracting competitive value with large food chains whose processes and marketing lines are territorially and logistically speaking, superior.

Information and communication technologies (TIC's) are a tool that offers the possibility of competing against the marketing and distribution systems of large food chains. In order to provide an agile tool for the MSMEs of the food sector, the mobile app "Apptojo" was created, which allows the food business (entrepreneur), offer their dishes, promote their business and specify orders with the final consumer (customer); by means of a geolocation system the client is offered the possibility of searching for 
dishes by categories, names, businesses, and throwing as a result the ones that are closest, at the same time suggesting dynamic dishes in order to generate consumer mobility in the future choices of the customer.

For the development of the mobile application "Apptojo" was based on a hermeneutical methodology, where the study background was the mobile applications of Uber Eats and Without Apron, because they are the most used in the country, but without reflecting an exponential growth as It was planned by the companies that developed them.

\section{$2 \quad$ What is in the Current Market?}

There is a variety of similar projects in the market, of which projects in the state of Michoacán can be highlighted, generated by engineering students in systems; the projects are omitted since none has been shown with a scientific or research approach of user behavior, joined to the disappearance of most of these projects attributed to mismanagement of distribution and marketing strategies.

For the purposes of the investigation, some projects were analyzed that, although they are not identical to the project, meet the expectations of the goals by individual sought. The project "FoodGo", intended to generate an increase in the information of a dish through situated analytics [13]; however, the results were not assertive in terms of a good market outcome, in addition to the fact that the application remained a prototype that, although it had a high expectation on the part of the users who used it, could not go to market, and therefore, it did not generate a commercial impact that could be quantifiable.

The NYAM project, part of the expectation of generating a link of recreational and necessity consumption in the end user, allowing him to find businesses near his location in real time, and filtering the best food businesses based on the opinion of other consumers [14], the project generated favorable results, a good market acceptance (for the area where it was applied), however the graphic quality of the application has not favored its expansion in the market, besides having a great potential for growth, if the application is submitted to a BPMN model [11] to be able to restructure its GUI and generate a fidelity segment in its users.

A project that was very useful to support the principles of user behavior, is "Differences in perceptions about food delivery apps between single-person and multi-person households", since it is an SEM that allows to determine the behavior of the relationships between multiple consumption structures (customers-businesses) [15]. The project has promising results that allow scalability in the medium term, however, the application was generated as an evaluation of the hypothesis and cannot be quantified or compared directly with Apptojo; although the hypothesis model is highlighted and recommended for future scope of the project.

\section{Methods}

The development of a mobile application requires an in-depth study of What? And for what? We want to do, considered as principles of innovation in quality models such as 
CMMI or Babok [11]. In order to comply with the previous premise, the agile development model SCRUM [8] was adopted, given that this model allowed working with a reduced work team (3 members) in charge of the application's development, algorithm, logic and software engineering, in addition to a team external to the development area, made up of professionals in the areas of graphic design, user experience, digital marketing and finance, with both teams approved in one, the application could be developed without major inconvenience.

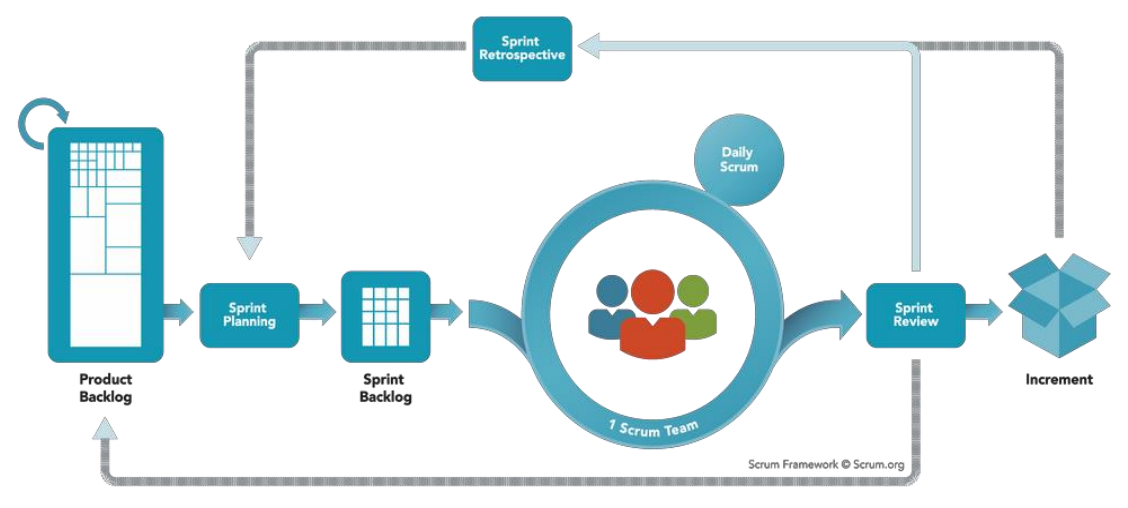

Fig. 1. SCRUM Methodology [8].

In the CMMI Dev Model v1.3 it is explained: "In Agile environments, the needs and ideas of the client are iteratively produced, elaborated, analyzed and validated. The requirements are documented in forms such as: user stories, scenarios, use cases, product backlog and iteration results (code under development in the case of software). What requirements will be addressed in a given iteration are determined by an assessment of the risk and by the priori- ties associated with the requirements left in the product's Product Backlog. What details of the requirements (and other artifacts) to document are deter- mined by the need for coordination (between team members, teams and sub- sequent iterations) and the risk of losing what has been learned. When the client is on the team, there may still be a need to separate the client and product documentation to allow multiple solutions to be explored. While the solution arises, the responsibilities of the derived requirements are assigned to the appropriate equipment" [12], so it is suggested the implementation of agile and simple acquisition techniques for the work teams that require it.

In order to replicate the development of mobile applications and CRM to generate an experience between customers and consumers, it is suggested to use the techniques listed below, with the aim of achieving results based on creativity and the conceptualization of ideas that generate added value in models technologies for electronic commerce.

\subsection{Workshops}

It is an effective technique to obtain information quickly from several people. 
- It is advisable to have a predefined agenda and pre-select the participants, following good practices for effective meetings.

- A neutral facilitator and a transcriptionist (other than the facilitator) can be used.

- You can use a common material on which to focus attention and talk, for example, a presentation with a breakdown of the process being studied or a flow chart.

They can be combined with other techniques such as interviews and questionnaires.

\subsection{Observation}

- Consists of studying the work environment of users, customers and project stakeholders (Stakeholders) [5].

- It is a useful technique when documenting the current situation of business processes.

- It can be of two types, passive or active.

- In passive observation, the observer does not ask questions, limited only to taking notes and not interfering in the normal performance of operations.

- In active observation, the observer can talk with the user.

\subsection{Brain Storm}

- It is a structured work session oriented to obtain as many ideas as possible.

- It is advisable to limit them in time, use visual aids and designate a facilitator.

- Rules are important, for example, the criteria for evaluating ideas and assigning a score, not allowing criticism of ideas and limiting discussion time.

- In the first phase, the largest number of ideas must be identified and then evaluated. All ideas must be considered and an idea must be limited to drowning or criticizing before having time to develop it [6].

In previous lines mentioned the axes that supported the development of the application: What? And for what?, which represents a challenge at the time of generating the means for development and the capture of requirements, especially in a mobile application that seeks to implement in a community where technology is not the determining factor in the models of business and marketing of the products, representing the challenge when generating projects that have a high level of innovation, creativity, disruptivity and that are candidates to generate a new experience scheme and facilitate the observation of the behavior of the agents they are part of the user experience. In the case of the mobile application, the following models were generated that fulfilled the expectations of the project:

The fulfillment of the Why? It was given to implement a model where the needs of the entrepreneur are functional and satisfied through the use of the application. The issues to solve in this method are the validity and verification of the expectations of the client, as well as the capacity of technological adoption by the employer; where the human factor plays an important role to assimilate the idea that an application is a prof- 
itable tool, sustainable and scalable to new technologies that facilitate the empowerment of the entrepreneur. The key in this section is to ask whether the objective set by the client [5], entrepreneur and the development team is satisfied for all involved, generating a harmony between the technological, commercial and marketing aspects.

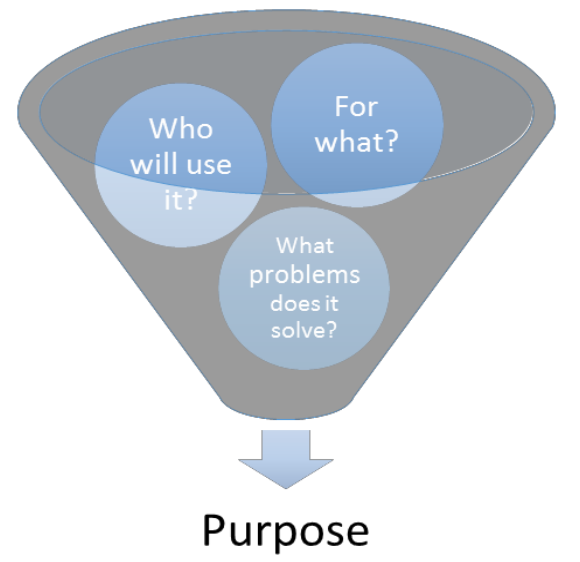

Fig. 2. Purpose delimitation model.

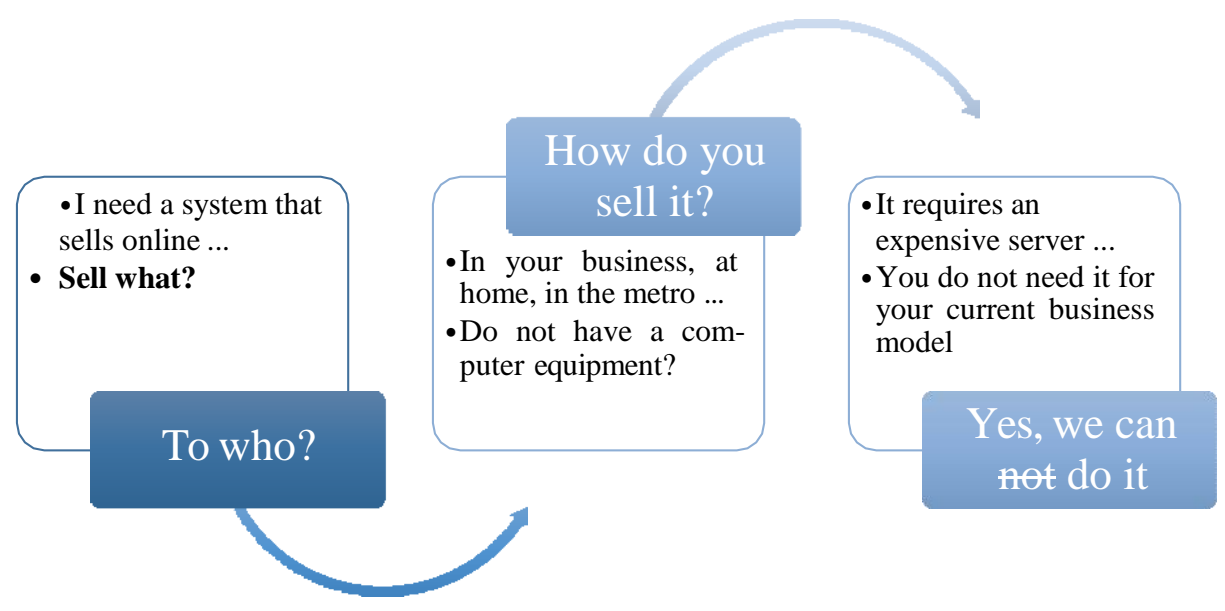

Fig. 3. Model of Why? (verification and validation).

When talking about the development of the application, technologies for mobile development were used that allowed to speed up the development in order to be able to focus on the conceptualization and engineering of project requirements, for this reason technologies such as Android Studio were used to codify the project using the Java and Kotlin programming languages.

As a backend system, Firebase was adopted, which is a real-time database system, messaging, mail server, test lab, among other services that were not used at the time. 
For the graphics processing, the Glide library was used, and the Openpay REST API was used as the payment system.

The complete system is based on a hybrid model of its own REST API, which allows the generation of payments by means of a credit / debit card only for the subscription of the business in the application.

\section{$4 \quad$ Results}

The generation and publication of the application was successfully achieved obtaining a plausible audience in the first days of organic dissemination in social networks of the application. Below are the graphics of the application in Play Store, as well as in operation.

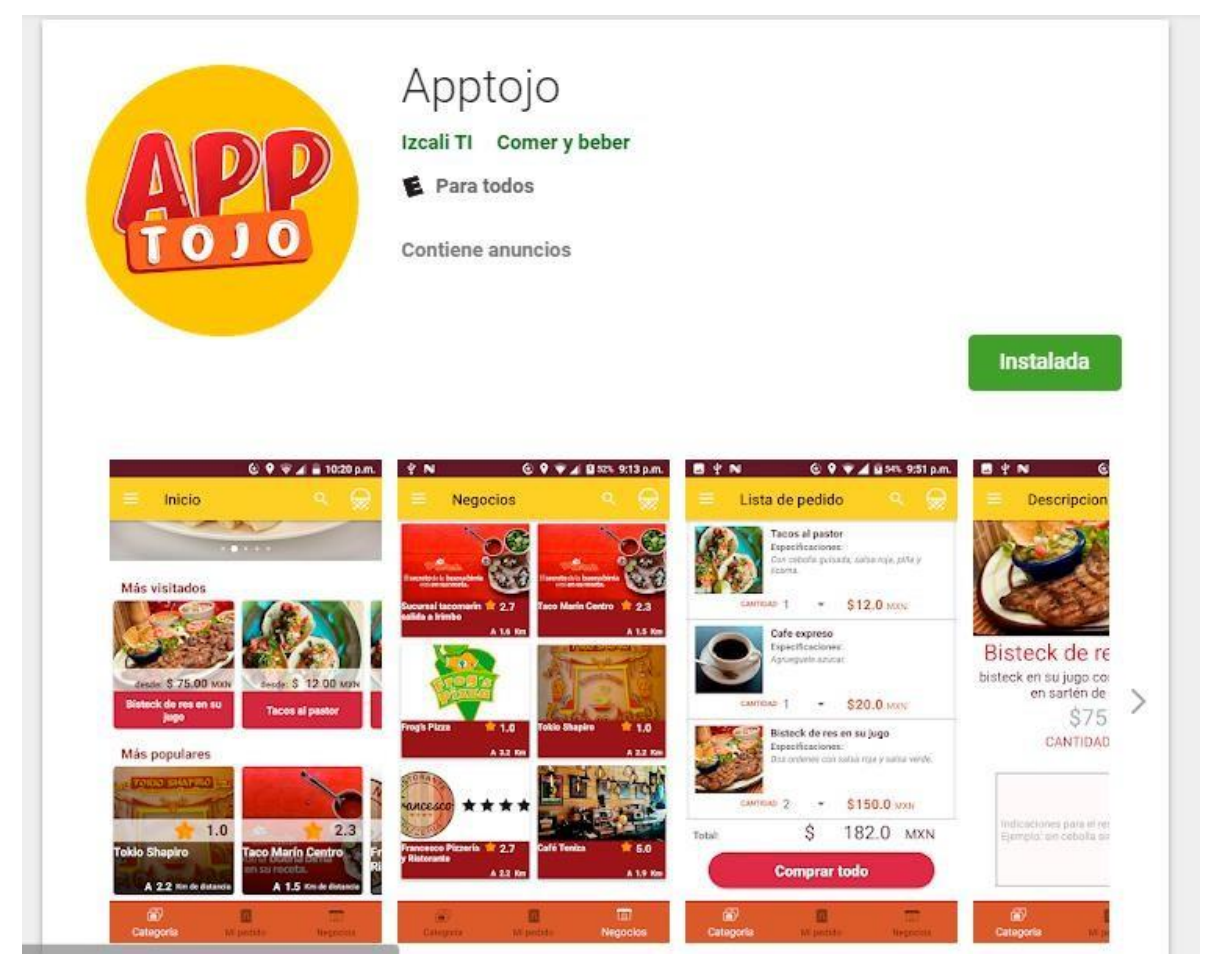

Fig. 4. Play Store view of the Customer version.

The generation of a launch page is essential to form a network of SEO positioning, then the view of the official website of the project is presented.

In the illustration 4 you can see the website of the Apptojo application; This site allows to obtain general information about the project, as well as to provide a download link for the application in Playstore. 
Apptojo: Behavioral Relationship between Consumers and Food Merchants through a CRM...
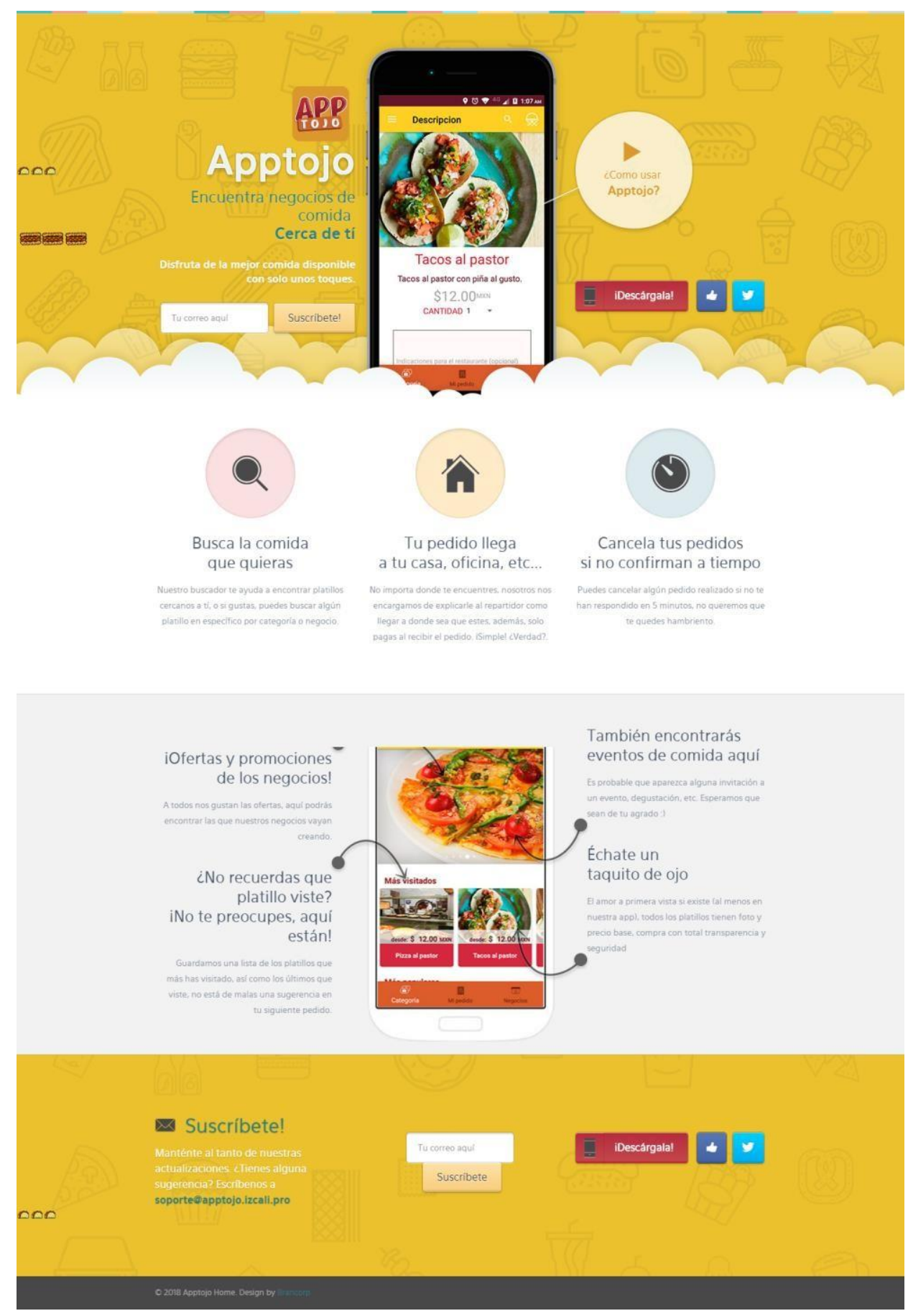

Fig. 5. Landing Page by Apptojo. 
Uriel Cambrón Hernández, Mariela Chávez Marcial

Experience of the mobile application for entrepreneurs:

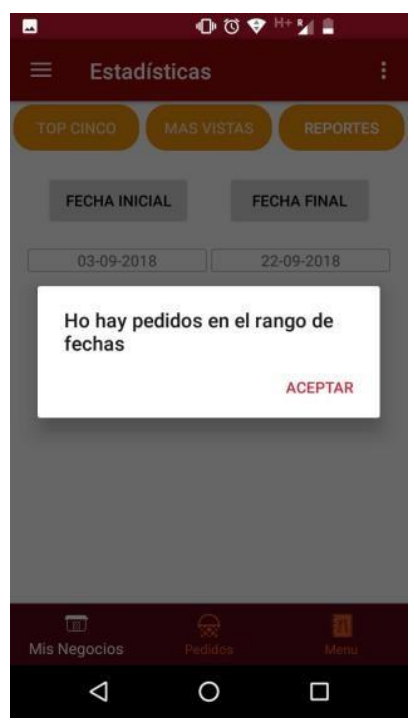

Fig. 6. Apptojo View for Companies.
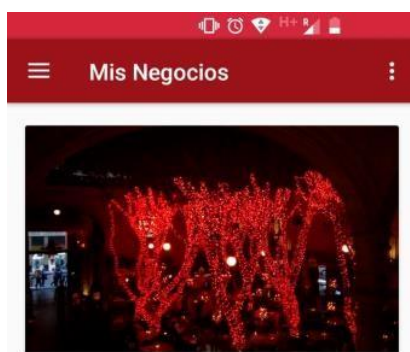

que bonito

Polanco Food

Calification: $\mathbf{5 . 0}$

ver más

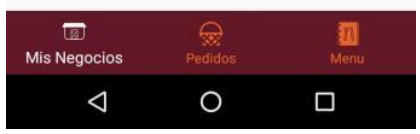

Fig. 8. Business view.

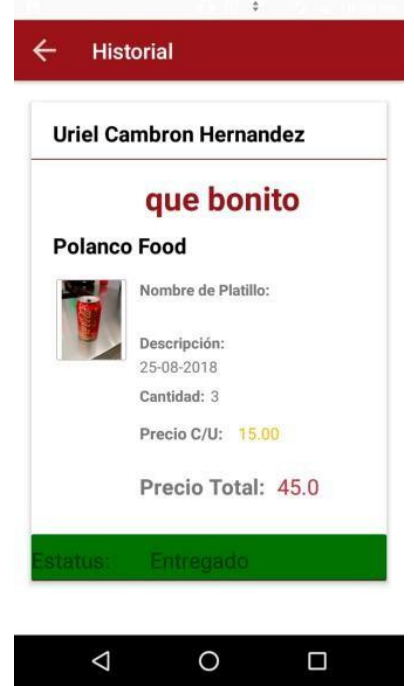

Fig. 7. View of Businessman's History
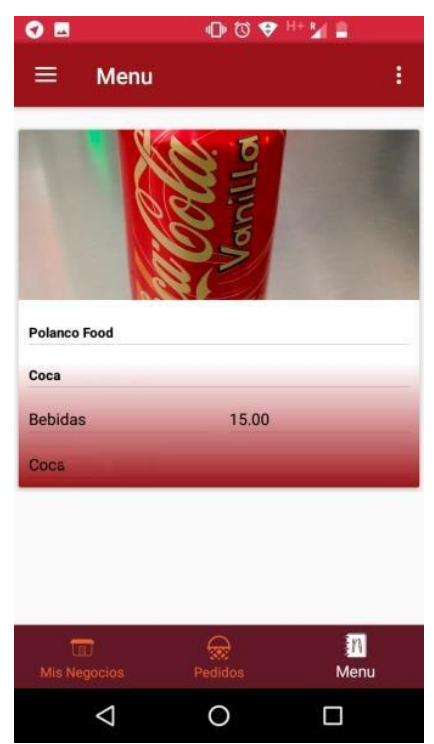

Fig. 9. Menu View.

The client application seeks to encourage you to consume a dish of those present in the list, for this a combination of graphic elements that generate appetite from the first view of the application was sought: 
Apptojo: Behavioral Relationship between Consumers and Food Merchants through a CRM...
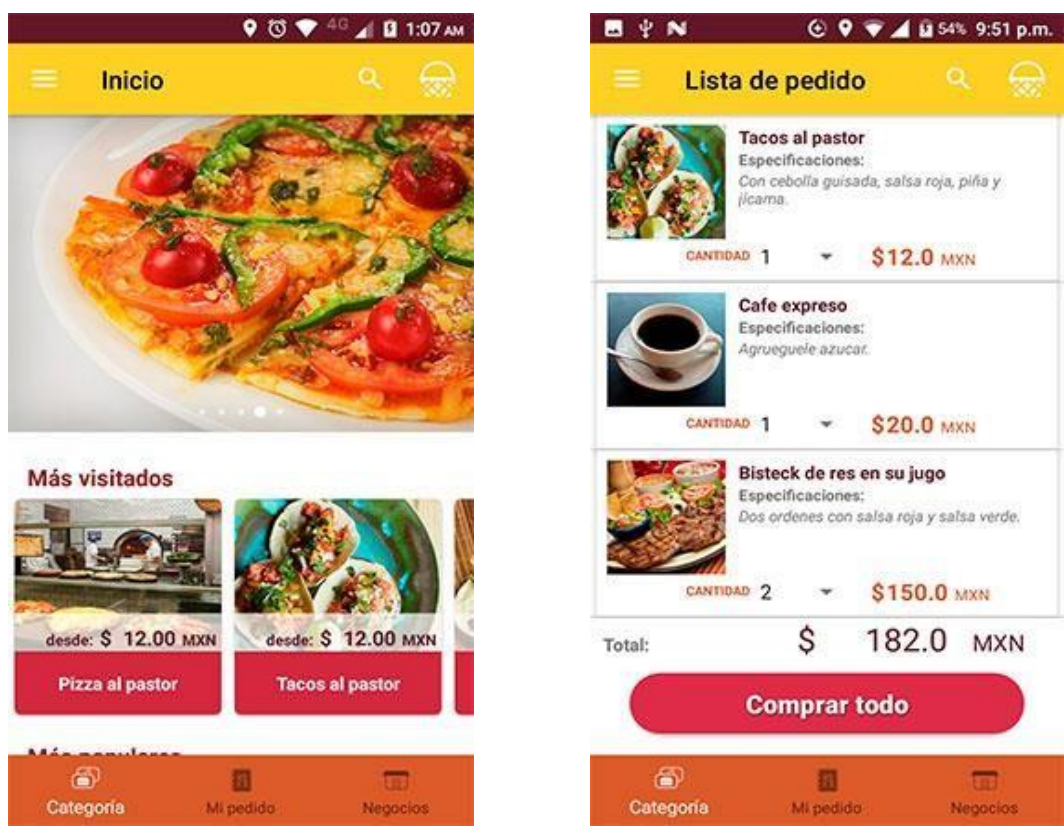

Fig. 10. Main view of the client application.

Fig. 11. List of the customer's order.

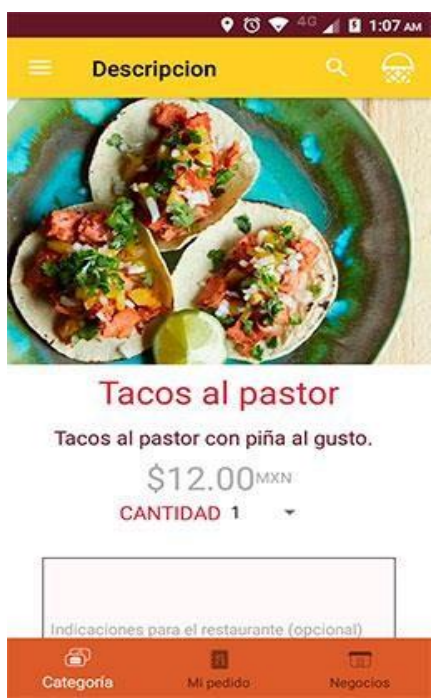

Fig. 12. Saucer view.

\subsection{Behavior Results Between Clients and Businesses}

By analyzing the behaviors among the different types of users, the following results were obtained: 


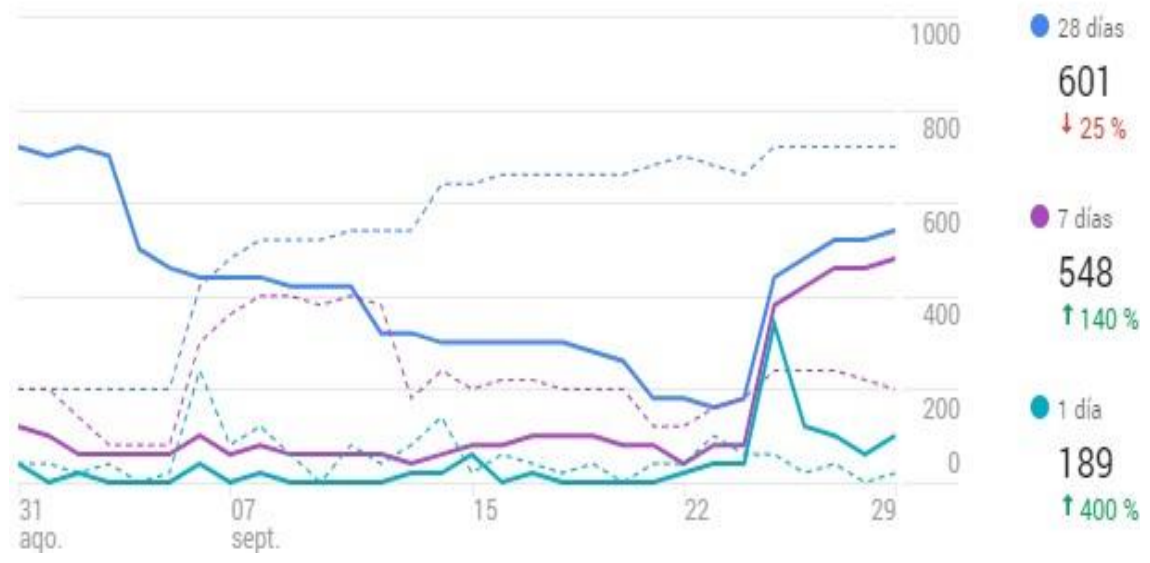

Fig. 13. Behavior between Customers and Merchants.

Through a growth rate of $140 \%$ in the last 7 days of evaluation of the application at the time of the cut (September 29), you can see the increase of $140 \%$ interaction in contrast to the audience captured 28 days ago, at the time of publishing the first version of the application in Play Store.

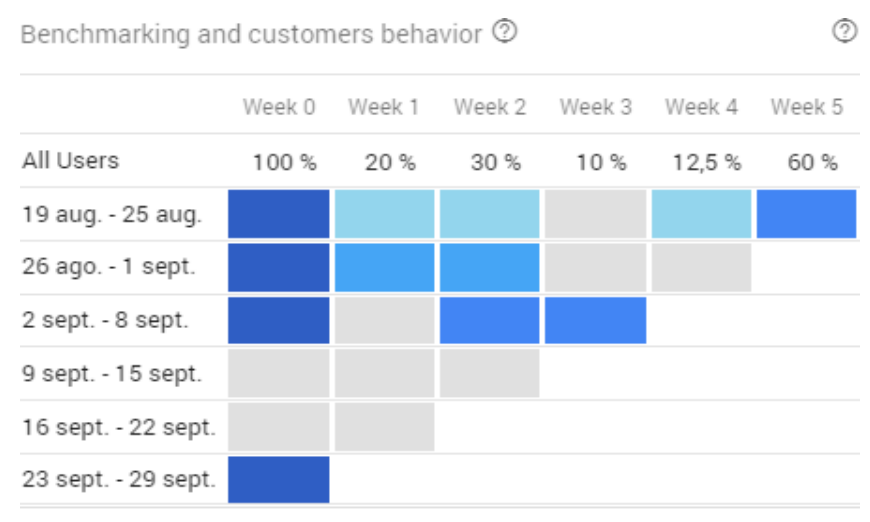

Fig. 14. Retention and Customer Behavior for Weeks.

\subsection{Times Used}

The interaction in the application requires less than 5 minutes to be able to generate an order (on the client's side), and approximately 20 minutes on the business side to be able to add an order. The average time in the application is $15 \mathrm{~min}$ and $59 \mathrm{~s}$, the above arises as a result of the interaction segments that lead to events, in which users generate interactions between them, confirming or canceling orders, as well as generating reports of sales, history and qualifications of orders. 


\section{Daily Users Interaction}

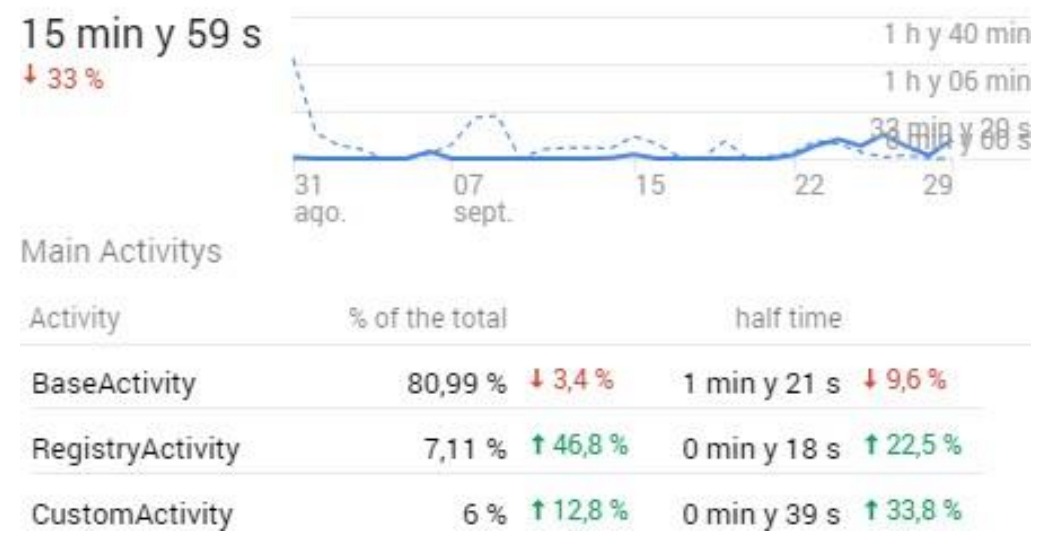

Fig. 15. Daily Users Interaction.

\subsection{Behavior of Users Who Downloaded the Application}

The behavior of the users (Table 1) was variable in terms of trends and the area from which the application was downloaded, along with the category as the application was found in the Play Store. Most of the audience was found in the category of Media and Entertainment, as well as purchases, technology, and lifestyle, with this goal is achieved to bring people looking for a style of digital consumption, with the MiPymes of Hidalgo, Michoacán, Mexico.

Table 1. Trends Behavior of Customers.

\begin{tabular}{|ll}
\hline \% de usuarios & Categorias \\
\hline $88,9 \%$ & Media \& Entertainmen...ics \& Animation Fans \\
\hline $88,9 \%$ & Shoppers \\
\hline $88,9 \%$ & Technology/Mobile Enthusiasts \\
\hline $70,4 \%$ & Lifestyles \& Hobbies/Shutterbugs \\
\hline $70,4 \%$ & Media \& Entertainment/Music Lovers \\
\hline $70,4 \%$ & Technology/Technophiles \\
\hline $66,7 \%$ & Banking \& Finance/Avid Investors \\
\hline $66,7 \%$ & News \& Politics/Avid News Readers \\
\hline $66,7 \%$ & Shoppers/Value Shoppers \\
\hline
\end{tabular}

\subsection{Scope and Relevance of the Application}

It was satisfying to find that the application was a great taste for the geo- graphic segment where the project began, however, the unexpected in the United States was unexpected, from which no scope was expected. In a saucer purchase report, a business reported an order generated with a telephone and location in the United States, with this the project's scalability and market vi- ability are foreseen to expand in a few years to 
the rest of the country.

The total number of visits generated in the last days was 621 customers, (the business data is kept in a confidential phase); Of which, $98.5 \%$ were in Mexico, while $1.5 \%$ were in the United States.

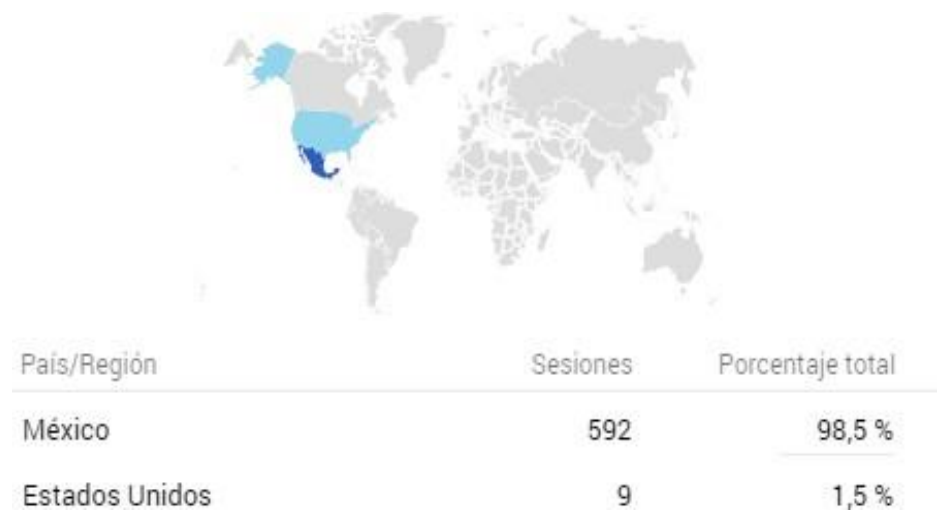

Fig. 16. Customer Location.

\section{$5 \quad$ Conclusions and Future Work}

The generation of projects and electronic marketing systems are a necessity to generate growth in global economic markets, allowing Mexico to incentivize the use of digital currencies to obtain goods and services.

Apptojo's application allows, among other things, the following:

- Food marketing,

- Promotion of local businesses,

- Consolidation of CRM systems for MiPymes [2],

- Exponential increase in sales in MiPymes,

- Facilitate the customer to obtain dishes close to the location,

- Generation of a Big Data system for the analysis of user behavior (which consumes, where, in what season).

The models of mobile applications that innovate in the conceptualization of CRM, should be a priority in the stack of projects of universities, approved to the private initiative, you can obtain significant results that are an engine of change for the benefit of society in which involves the development and implementation of a technologicalproject.

We thank the honorable committee of HIS 2018 for the opportunity to present the progress and results of this project, wishing success in the future research work carried out, in order to promote scientific and technological development that allows the transcendence of knowledge in humanity. 


\section{References}

1. del Barrio, L.: Del Business al e-Business en tiempos de crisis. Gestión 2000 (2003)

2. Escobar, M.: El Comercio Electrónico, perspectiva presente y futuro en España. Fundación AUNA (2000)

3. Terceiro, J.B., Matías, G.: Digitalismo, el nuevo horizonte sociocultural. Taurus (2001)

4. García-Valcárcel, I., Munilla, E.: e-Business Colaborativo. FC Editorial (2003)

5. Eisenmann, T.R.: Internet business models: text and cases. McGraw-Hill (2002)

6. Chaffey, D.: E-business and E-commerce management, 2nd edition. Prentice Hall (2003)

7. Ontiveros, E.: La economía en la Red, Nueva Economía, nuevas finanzas. Taurus (2001)

8. Schwaber, K., Sutherland, J.: The Scrum Guide ${ }^{\mathrm{TM}}$ (2017)

9. Javier-Maestre, J., Almeida, C.: La Ley de Internet: regimen jurídico de los servicios de la Sociedad de la Información y el comercio electrónico. Servidoc (2002)

10. Vázquez, C.: Comercio electrónico, firma electrónica y servidores: Comentarios y anexo Legislativo. Editorial Dijusa (2002)

11. International Institute of Business Analysis (IIBA): BabokA guide to the business Analysis Body of Knowledge (2015)

12. Equipo del Producto CMMI.: CMMI para Desarrollo, Versión 1.3 CMMI-DEV, V1.3. Software Engineering Institute (2010)

13. Ochoa, A., Ruiz-Jaimes, M., Leon, S., Toledo, Y., Ramírez, I.: Decreased Business Uncertainty by Using Bayesian Networks for the Paradigm Shift in Business Simulator. Research in computing science (2016)

14. Rodríguez-Díaz, A., Juárez-Martínez, U., Peláez-Camarena, G., Muñoz-Contreras, H., Olivares-Zepahua B.A.: Intercesión en invocaciones con la reflexión de Java. Research in computing science (2016)

15. Urbina-Delgadillo, M.L., Figueroa, M.A.A., Peláez-Camarena, G., Alor-Hernández, G., Sánchez-García A.I.: Mixing Scrum-PSP: Combinación de Scrum y PSP para mejorar la calidad del proceso de software. Research in Computing Science (2016)

16. Piña-García, C.A., Gu, D., Gershenson, C., J. Siqueiros-Garca, M., Robles-Belmont, E.: Exploring Dynamic Environments Using Stochastic Search Strategies. Research in computing Science (2016)

17. Safi, H., Jaoua, M., Belguith-Hadrich, L.: Learning-to-Rank for Hybrid User Profiles. Research in Computing Science (2017)

18. Abaoa, R.P., Malabananb, C.V., Galidoc, A.P.: Design and Development of FoodGo: A Mobile Application using Situated Analytics to Augment Product Information. Procedia Computer Science (2018)

19. Cho, M., Bonn, M.A., Li, J.: Differences in perceptions about food delivery apps between single-person and multi-person households. International Journal of Hospitality Management (2018)

20. Isabela, E., Drona, J., Fadhilah, N., Tanoto, D.F., Harefa, J., Prajena, G., Chowanda, A.A.: NYAM: An Android Based Aplication for Food Finding Using GPS Procedia Computer Science (2018) 